\title{
Comparison of different roll motion controls for a 49-m mono-hull passenger ship in beam waves
}

\author{
Franklin J. Domínguez R., $\mathrm{PhD}^{1}$, and José R. Marín López, $\mathrm{PhD}^{2}$, \\ ${ }^{1}$ Doctoral Program, Universidade da Coruña - UDC, A Coruña, Spain, f.j.dominguez.ruiz@udc.es \\ ${ }^{2}$ Facultad de Ingeniería Marítima y Ciencias del Mar, Escuela Superior Politécnica del Litoral, Ecuador, jrmarin@espol.edu.ec
}

\begin{abstract}
Influence of two roll control systems, one passive and another active, are compared in a 49-m length overall mono-hull ship in beam waves. For this objective, time integrations of the uncoupled ship roll response differential equation considering nonlinear behavior of righting arm and damping moments, are developed; fourth-order Runge-Kutta algorithm with constant time interval is employed. These numerical simulations are performed with the original naked hull, then including the effect of bilge keels, the effect of active foils, and, finally with bilge keel and the active foil control system. The righting arm is interpolated from the original values with a $7^{\text {th }}$ order polynomial. Damping moment is calculated for different amplitudes and cubically interpolated as a function of roll velocity. Excitation moment from irregular waves is applied at sea states 2, 3 and 4, considering a combination of 1000 harmonic components. To estimate the moment due to the active foil control, typical values for the constants of the transfer function are employed, based on its natural frequencies. Wind moment is estimated with sea state mean velocity and lateral projected area of the ship. With the time registers, spectral densities of roll angle and rolling acceleration are calculated using Fourier transforms, and finally, RMS values are estimated from area under those curves. A comparison shows the reduction in roll angle and rolling acceleration when the $17-\mathrm{m}^{2}$ bilge keels are installed, and when the 6- $\mathrm{m}^{2}$ active fins are acting.

Keywords - roll stabilization, bilge keel, active foil control.
\end{abstract}

\section{INTRODUCTION}

A ship in waves oscillates as a rigid body with translations and rotations, which may cause sickness to passengers and eventually may take the vessel to capsize. To reduce ship motion there are several devices with different levels of complexity and cost. The goal of some of these accessories is to increase the damping of the motions, while the active ones produce a moment that opposes the wave action.

Some of the previously mentioned devices or systems for roll stabilization are passive and others are active, [1], [2] and [3]. Of course those in the first group, for example, bilge keels and U-tanks without active control, are cheaper and more simple to install but may represent an increment in ship resistance even in conditions when they are not necessary. Active U-tanks with controlled valves or fins, systems of the second type, require electric power for its functioning but operate only when they are required. So the decision to install one type of stabilization usually considers not only the desired reduction in motion but also investment, space and power requirements.

To size one of the simplest devices for ship roll control, bilge keels, Watson [3] presents a procedure based on the block coefficient and recommendations for maximum main

Digital Object Identifier (DOI):

http://dx.doi.org/10.18687/LACCEI2020.1.1.253

ISBN: 978-958-52071-4-1 ISSN: 2414-6390 dimensions. Also, Bhattacharyya [1] may be used for preliminary estimation of roll damping for these appendages. The selection of active foils is based on the desired moment generated by these fins which opposes that exerted by waves, [4]. Normally it is considered that the angle of rotation must be less than about 28 degrees, however, due to the stall effect of the foils, the expected best performance is achieved at around 16 degrees. All of these references are directly applicable to very large ships.

There are several comparisons between ways of ship roll stabilization. For example in [2], Pérez classifies different systems for roll reduction and describes the advantages and disadvantages of each of them. Also in [5], it is highlighted that bilge keels should be the first choice, and, that active fins may be selected when cost is not important between other factors. In reference [6], a comparison of roll stabilization between fins and anti-rolling tanks, both active is presented for a large cruise ship, $275.7 \mathrm{~m}$ length overall. In this case, the ship lateral area is enormous and the load by wind action produces large heel angles. Their computations show that both active systems are able to reduce the ship roll motion due to waves and heel due to wind. In this previously mentioned reference, there is no comparison of the practical implementation of the systems.

In the present work, two systems of roll stabilization for a 49-m length overall ship are compared. This vessel, considered small, provides tourist trips between Galápagos islands, and the influence of bilge keels and an active fin [7] with those of the original naked hull, as reducers of roll motion are analyzed. This comparison considers the reduction in response to irregular beam waves, complexity and cost of installation.

\section{RESPONSE TO IRREGULAR BEAM WAVES}

\section{A. Equation of motion}

Applying Newton's second law of motion, from Belenky [8] the uncoupled nonlinear roll equation, including external moments due to the action of waves, foils, and wind, is:

$$
\begin{aligned}
& I_{x x}{ }^{\prime \prime} \ddot{\phi}+B(\dot{\phi})+\Delta G Z=M_{\text {waves }}(t)+M_{\text {foil }}+M_{\text {wind }}(t) \\
& \text { where: } \\
& I_{x x}{ }^{\prime} \text { : virtual mass moment of inertia, } \Delta k_{x x}{ }^{\prime \prime 2} / g \\
& B(\dot{\phi}) \text { : damping moment, } \\
& \Delta G Z \text { : righting moment, with } \Delta, \text { as the ship } \\
& \text { displacement, and GZ the righting arm, } \\
& M_{\text {waves }}: \text { moment due to wave action, } \\
& M_{\text {foil }} \text { : moment due to the action of the foil, and, }
\end{aligned}
$$

$18^{\text {th }}$ LACCEI International Multi-Conference for Engineering, Education, and Technology: "Engineering, Integration, and Alliances for a Sustainable Development" "Hemispheric Cooperation for Competitiveness and Prosperity on a Knowledge-Based Economy", 27-31 July 2020, Virtual Edition. 
$M_{\text {wind }}$ : moment due to wind pressure.

Dividing (1) by the virtual mass moment of inertia the following differential equation is used for the numerical simulations:

$$
\begin{aligned}
\ddot{\phi}+\frac{\left(2 \mu \dot{\phi}+\beta \dot{\phi}|\dot{\phi}|+\delta \dot{\phi}^{3}\right)}{I_{x x}{ }^{\prime \prime}}+\frac{g G Z(\phi)}{k_{x x}{ }^{\prime \prime 2}} \\
=m_{\text {waves }}(t)+m_{\text {foil }}(\dot{\phi})+m_{\text {wind }}((\phi)
\end{aligned}
$$

where $k_{x x}$ "' is the virtual gyration radius and $g$ is gravity acceleration. Damping moment is expressed as a cubic polynomial, and, assuming that the initial stability range will be exceeded, righting arm, $G Z$, will be interpolated as a function of roll angle. Moments from waves, foils, and wind appear in units $\left(1 / \mathrm{s}^{2}\right)$, and are named with lower case in the previous equation.

\section{B. Description of the vessel}

The ship analyzed in this work is $49.2 \mathrm{~m}$ in length overall, built with steel, mono-hull, cruiser type and provides tourist trips in the Galápagos Island, Fig. 1. The ship lines include a bow bulb and transverse sections with a chine.
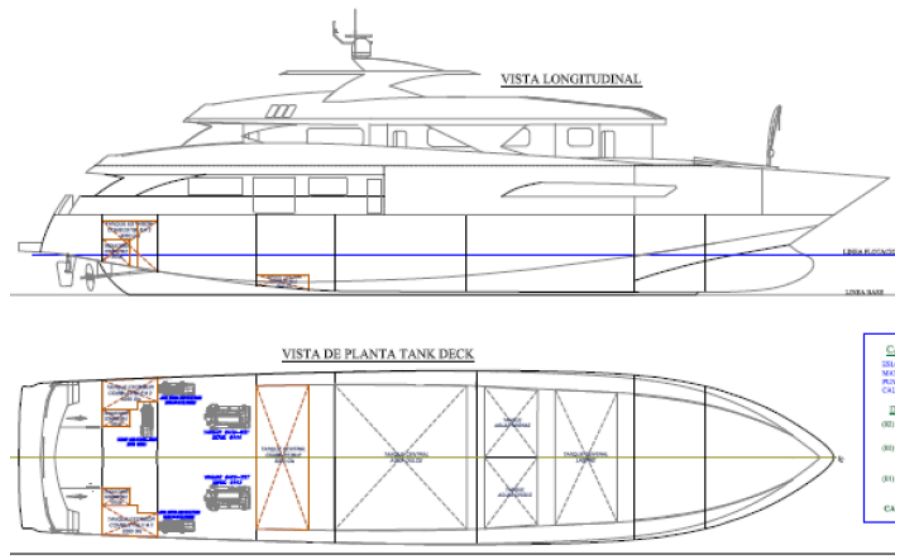

Fig. 1 General arrangement plan

For this analysis, two ship loading conditions are considered, consumables at full and $10 \%$, with the following characteristics, see Table I. The maximum velocity of the ship is 12 knots. The dry and virtual gyration radii are assumed as $35 \%$ and $45 \%$ of the ship's beam.

TABLE I

SHIP LOADING CONDITIONS

\begin{tabular}{|l|c|c|c|}
\hline & Load condition 1 & Load condition 2 & Units \\
\hline$L_{w l}$ & 44.24 & 41.40 & $\mathrm{~m}$ \\
\hline$B$ & 9.16 & 9.04 & $\mathrm{~m}$ \\
\hline$T$ & 2.36 & 2.21 & $\mathrm{~m}$ \\
\hline Trim (+by stern) & 0.27 & -0.19 & $\mathrm{~m}$ \\
\hline Displacement & 462.8 & 406.3 & tons \\
\hline$K G$ & 4.352 & 3.88 & $\mathrm{~m}$ \\
\hline$k_{x x} / B($ dry) & 0.32 & 0.32 & $\mathrm{~m} / \mathrm{m}$ \\
\hline$k_{x x}{ }^{\prime} /$ B $($ virtual) & 0.45 & 0.45 & $\mathrm{~m} / \mathrm{m}$ \\
\hline foroll & 0.142 & 0.178 & $\mathrm{~Hz}$ \\
\hline
\end{tabular}

\section{Moment due to wave action}

Moment due to wave action is estimated summing a number of harmonic components. The amplitude of each harmonic is obtained multiplying the moment developed by a unit amplitude regular wave $m_{1 i}$ multiplied by the corresponding wave amplitude $A_{i}$ from the sea elevation spectrum:

$$
M_{i}(t)=A_{i} m_{1 i} \cos \left(\omega_{i} t+\theta_{i}\right)
$$

Wave moment per unit wave amplitude $m_{1 i}$ is estimated applying SCORES computer program from Raff [9]; this program uses $2 \mathrm{D}$ hydrodynamic sectional properties from Tasai [10] and strip theory. Sea elevation spectrum is calculated using Brettschneider two-parameter formulation [11], see Fig. 2, and decomposed in an adequate number of components, each one with amplitude:

$$
A_{i}=\sqrt{2 S^{+}\left(\omega_{i}\right) \Delta \omega}
$$

where $S^{+}(\omega)$ is the spectral density of sea elevation, and $\Delta \omega$ is the segment width of each component. For this study, typical for the area of vessel operation, sea states, SS, 2, 3 and 4 are considered. Wavelength is varied from 5 to $299 \mathrm{~m}$ with increments of $6 \mathrm{~m}$, Fig. 3. Notice in Fig. 2 that the modal frequency for SS3 is very close to the roll natural frequency in the second load condition.

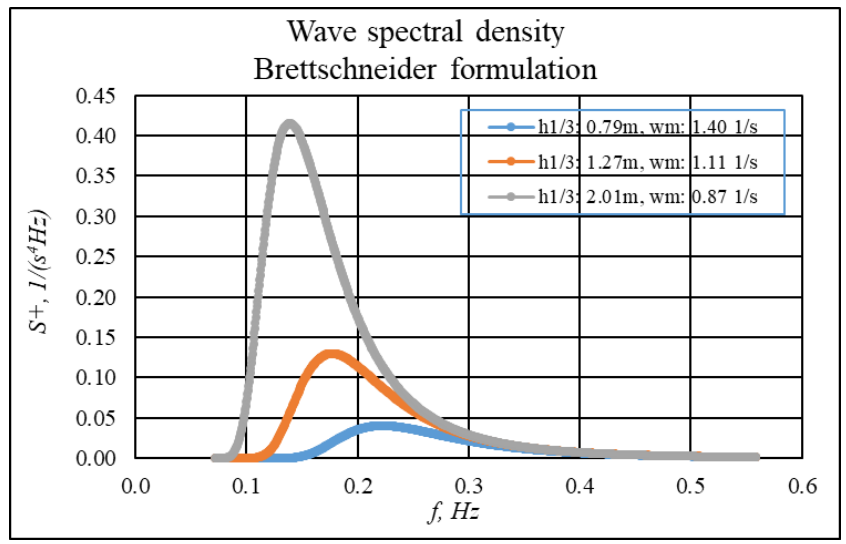

Fig. 2 Spectral density for sea state 3 with Brettschneider formulation

Replacing equation (4) in (3) and (4) produces the amplitudes of 1000 harmonic components of the wave moment which will be acting on the ship. For SS3, these results are shown in Fig. 4.

\section{Roll damping moment}

This moment is calculated by combining wave generation, estimated from irrotational flow, and viscous components for the two shipload conditions. The first component is taken from SCORES results [9], with no ship velocity. The second part, which in turn includes friction, eddies, lift, and bilge keel 
components, is estimated applying Himeno method [12]; this method includes the influence of ship velocity. For the time integration of ship motions, two situations are considered, without and with bilge keels. Bilge keels are $12.41 \mathrm{~m}$ long with $0.672 \mathrm{~m}$ in span, for a one side area of $8.3 \mathrm{~m}^{2}$, [7]. In Fig. 5, for all four cases, cubic polynomial regressions are also presented for the damping moment divided by the virtual inertia. The influence of bilge keels is very large, and for large values of roll velocity, its nonlinearity is evident.

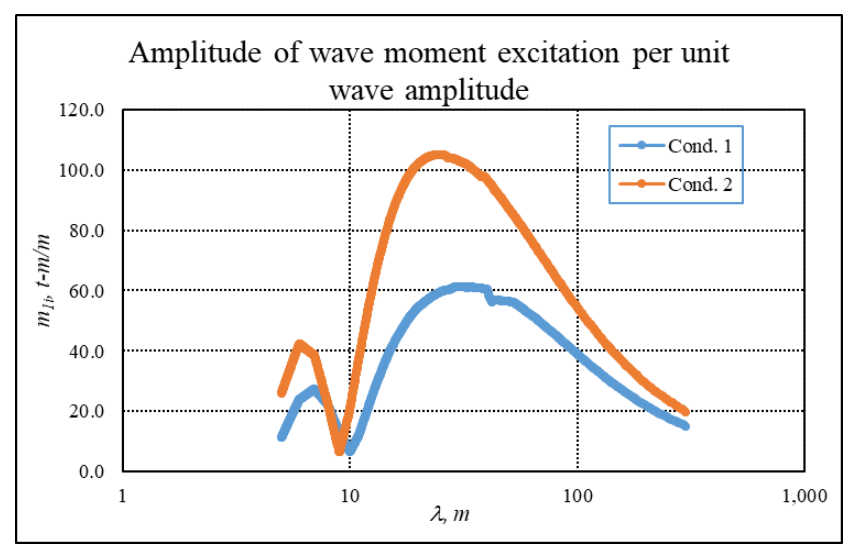

Fig. 3 Wave moment with unit wave amplitude

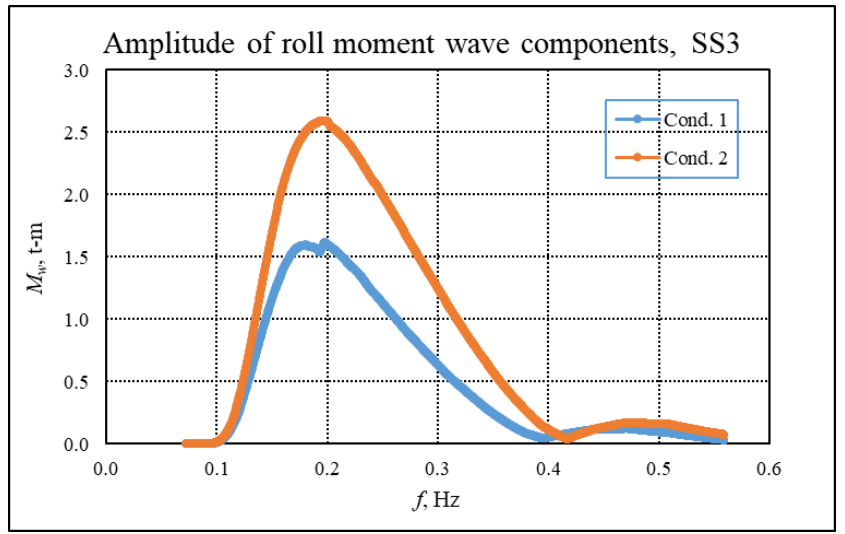

Fig. 4 Amplitude of wave moment components for SS3

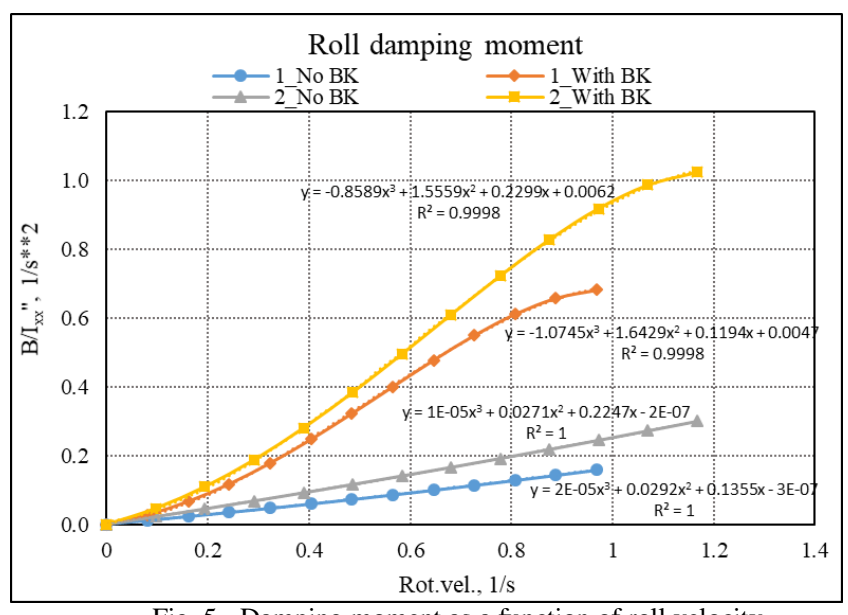

Fig. 5.- Damping moment as a function of roll velocity

\section{E. Righting moment}

From ship hydrostatics, the righting arm curve for both loading conditions are calculated, and they are interpolated with polynomials of $7^{\text {th }}$ order, see Fig. 6. From the polynomial interpolations, $G M$ is taken as the coefficient of the linear term.

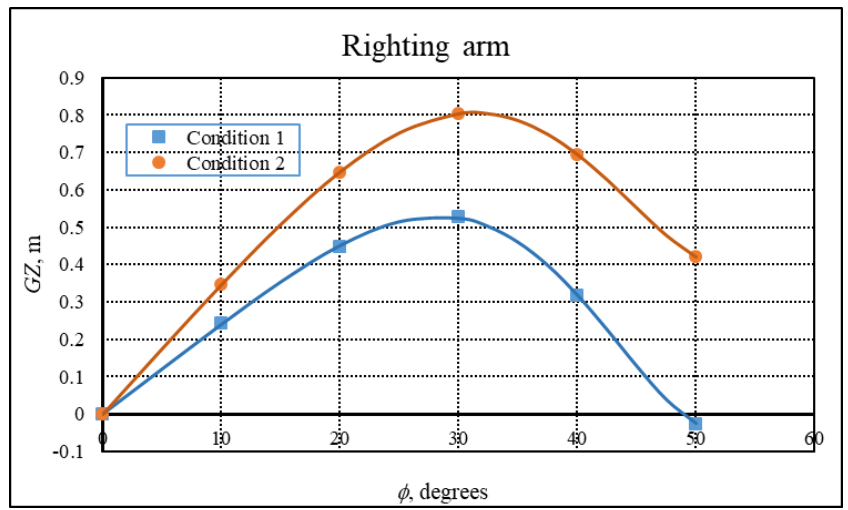

Fig. 6.- Polynomial variation of righting arm, $G Z$

\section{F. Moment due to the action of the foils:}

Since in this work, it is desired to compare the contribution of an average system of motion control, not to develop its full design, its main characteristics are selected using standard values. From Lloyd [4] it is taken the following diagram for a typical roll stabilization system, see Fig. 7. The most important part is the Controller, which after a Measured roll angle value $x_{4}$, defines a fin angle $\alpha_{D}$, trying to produce a moment $F_{F 4}$, which opposes the one produced by waves, $F_{W 4}$.

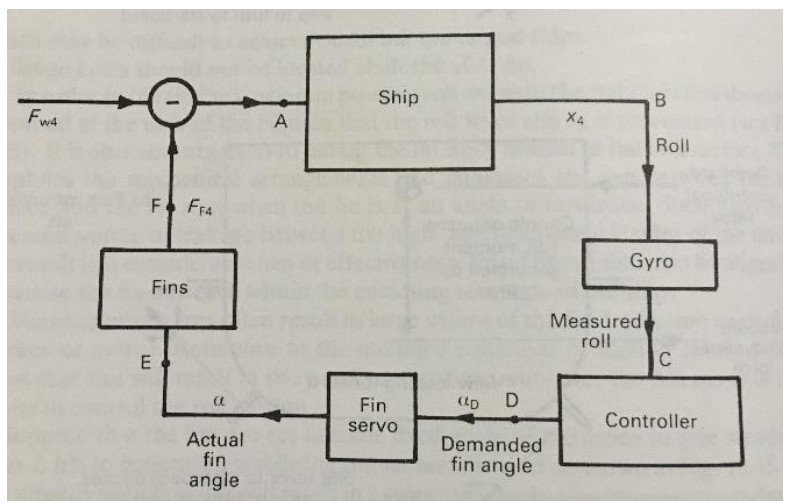

Fig. 7.- Block diagram for a ship with roll stabilizer fins (Lloyd, [4])

According to Lloyd, the transfer function of the fin controller, which relate the demanded fin angle $\alpha_{o}$, to the ship roll angle $x_{4}$, both with Laplace transform, generally have the form:

$$
H(s)=\frac{\mathrm{A}(s)}{\Phi(s)}=K_{G} K_{U} \frac{K_{1}+K_{2} s+K_{3} s^{2}}{b_{1}+b_{2} s+b_{3} s^{2}},
$$

where $K_{G}$ and $K_{U}$ are overall and speed-dependent gain settings; $K_{1}, K_{2}$, and $K_{3}$, are roll angle, roll velocity and roll acceleration sensitivities; $b_{1}, b_{2}$, and $b_{3}$ are fixed control coefficients; $s$ is the Laplace transform operator $(d / d t)$. The convolution of the inverse Laplace transform of this transfer 
function $h(t)$, with the roll angle $\phi(t)$, results in the actual angle for the fin, $\alpha$; fin servo phase shift is neglected:

$$
\alpha(t)=\int_{0}^{\infty} h(\mathrm{~T}) \phi(t-\mathrm{T}) d \mathrm{~T} .
$$

In this work, the transfer function (5) is defined as follows. Fixed control coefficients are chosen as $b_{1}=1.0, b_{2}=0.5$ and $b_{3}=0.05$, which are typical values according to the mentioned reference. Values of ship motion sensitivities are determined considering lag of ship response with respect to the foil action $\left(-70^{\circ}\right)$ and are also dependent on the natural frequency of roll. Also to simplify this process, $K_{l}=0$, and $K_{3}=1$.

After all parameters of the transfer function are selected, this function divided by the common coefficient is rewritten as:

$$
H(s)=1-\frac{d s+e}{(s+a)^{2}+b},
$$

where $a, b, d$, and $e$ are constants. Its Laplace inverse transform is:

$$
h(t)=\delta(t)-d e^{-a t} \cosh (\sqrt{b} t)-(e-a d) e^{-a t} \frac{1}{\sqrt{b}} \sinh (\sqrt{b} t),
$$

where $\delta(t)$ is the delta Dirac function.

The exponential, $e^{-a t}$, present in the last two terms of the previous expression makes this function to decay rapidly, so we can truncate the convolution integral (6) after an adequate time. In the following figure, it is shown the sum of the last two terms of $h(t)$ function vs time, which is used for simulations in the two load conditions, see Fig. 8. In Table II values for constants in the expression (7) for $h(t)$ are presented.

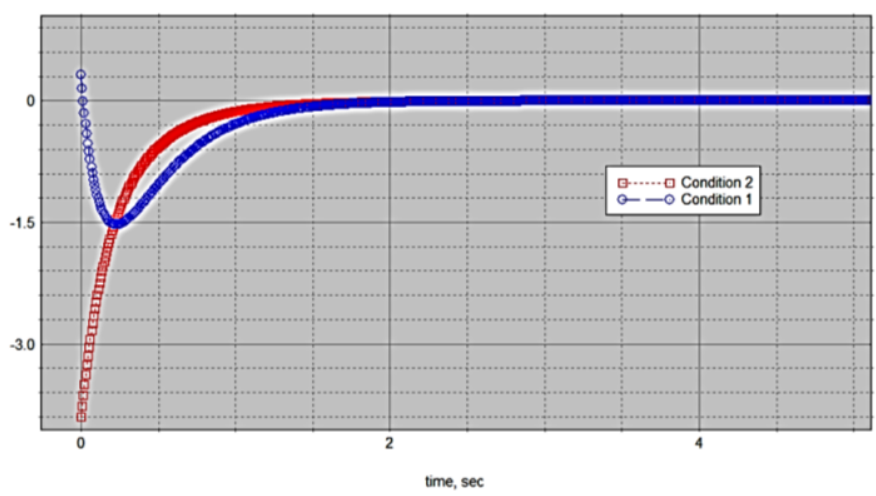

Fig. 8.- Transfer functions in the time domain

TABLE II

DEFINITION OF TRANSFER FUNCTIONS

\begin{tabular}{|c|c|c|}
\hline & $\begin{array}{c}\text { Load condition } \\
1\end{array}$ & $\begin{array}{c}\text { Load condition } \\
2\end{array}$ \\
\hline$a$ & $0.5 \mathrm{E}+01$ & $0.5 \mathrm{E}+01$ \\
\hline$b$ & $-0.5 \mathrm{E}+01$ & $-0.5 \mathrm{E}+01$ \\
\hline$d$ & -0.3138 & $0.3902 \mathrm{E}+01$ \\
\hline$e$ & $0.2 \mathrm{E}+02$ & $0.2 \mathrm{E}+02$ \\
\hline
\end{tabular}

The next step is to obtain the foil angle through the convolution of the transfer function (8) and values of the roll angle. This integration is developed numerically, and since the convolution decays in time, this summation stops when the transfer function in the time domain is smaller than 1.0E-20. Also, these results are multiplied by a final gain so that maximum values of the foil angle are not extremes, less than 28 degrees according to the manufacturer [7].

Once the angle of attack is specified by the controller, the lift generated by the stabilizer foil is estimated with the formula:

$$
L_{\text {foil }}(\dot{\phi})=C_{L} \frac{1}{2} \rho S V^{2},
$$

where the lifting coefficient $C_{L}$ depends on the angle of attack; lag of foil moment is neglected. The lifting coefficient according to the thickness distribution and aspect ratio is interpolated from [13], with a polynomial of $5^{\text {th }}$ order, Fig. 9.

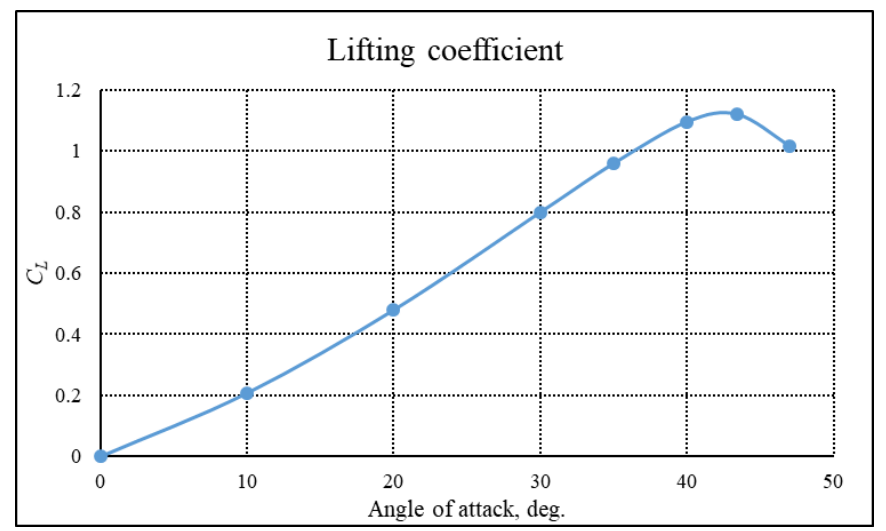

Fig. 9.- Lifting coefficient

With the lift from (9), the moment generated by the foils is calculated with respect to the position of the ship centroid:

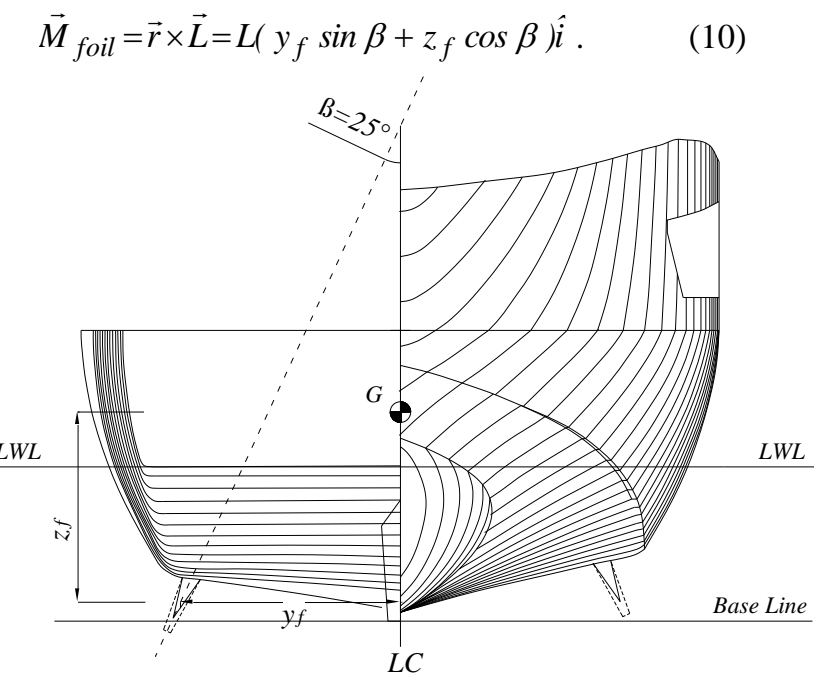

Fig. 10.- Geometry of section with foil

where $\beta$, is the angle of the foil and the vertical, and $\left(y_{f}, z_{f}\right)$ is the position of the centroid of the foil in the reference system 
(at CG of the ship). The area of each one of the foils is $3.02 \mathrm{~m}^{2}$, and the angle with respect to vertical is $25^{\circ}$. Positions in meters of the centroid of the foil from ship's center of gravity in (10) are: $\left(y_{f}=3.38, z_{f}=4.04\right)$ and $\left(y_{f}=3.38, z_{f}=3.57\right)$, in the two ship loading conditions, Fig. 10.

\section{G. Wind action:}

In Kim [6], the moment due to wind action is evaluated with the following expression, developed by Fujiwara [14]:

$$
M_{\text {wind }}=C_{H} C_{A K}\left(\psi_{A}\right) q_{A} A_{L} H_{L}
$$

where $C_{H}$ is the heel effect coefficient, $C_{A K}$ is the heel moment coefficient, $q_{A}$ is the dynamic pressure in the actual sea wind conditions, $A_{L}$ is the lateral projected area, and, $H_{L}$ is the mean height of the ship (equal to $A_{L} / L_{O A}$ ), see Fig. 11.

Heel effect coefficient, $C_{H}$, in (11) is evaluated from model experiments, for different values of heel angle. From the previously mentioned reference, this coefficient is estimated as a linear function of the heel angle, by:

$$
C_{H}=1.0+\text { cons } \tan t * \phi .
$$

In the present work, an average value of -0.00738 is taken for the constant in the previous expression (12), from Kim [6], which is based on more recent experiments; heel angle is expressed in degrees.

Heel moment coefficient, $C_{A K}$ depends on the relative wind direction $\psi_{A}$. Kim [6], presents the variation of this coefficient for different relative directions, and for $\psi_{A}=90^{\circ}$, wind from the beam, this coefficient is close to a value of 1.0 , which is employed in this work.

The dynamic pressure is calculated according to Fujiwara's method, [14]:

$$
q_{A}=q_{T}+q_{S}+2 \sqrt{q_{T} q_{S}} \cos (\psi+\beta) .
$$

The term $q_{S}$ in (13) is evaluated with the velocity of the ship, $U: 1 / 2 \rho_{A} U^{2}$, with a value of $1.1923 \mathrm{~kg} / \mathrm{m}^{3}$ for the density of the air, $\rho_{A}$. In the cosine of the last term, angle $\beta$ is the drift, and $\psi$ is the angle of wind direction, $90^{\circ}$; taking null drift, the cosine in the term is zero. The first term $q_{T}$ is estimated as:

$$
\begin{aligned}
& k_{q} q_{M}+\left(1-k_{Q}\right) q_{H L}, \\
& \text { where } q_{H L}=1 /\left.2 \rho_{A} U_{T}^{\prime 2}\right|_{H L}, \\
& \text { and, } q_{M}=\frac{1}{H_{L}} \int_{H_{L}} 1 / 2 \rho_{A} U_{T}^{\prime}\left(z_{A}\right)^{2} d z_{A}, \\
& k_{q}=2.162\left(\frac{q_{M}}{q_{H L}}\right)^{2}-2.422+1.260 .
\end{aligned}
$$

The wind profile, $U^{\prime}(z)$ in the integral (15) is developed following Recommended Practice C205 from DNV ship classification society, [15]:

$$
U(z)=U(H)\left(1+\frac{1}{k_{a}} \sqrt{\mathrm{K}} \ln \frac{z}{H}\right)
$$

with the ten minutes mean wind speed at $10 \mathrm{~m}$ height above the still water level used as wind parameter $U(H)$; for sea state 3 , wind velocity is 15 knots. Von Karman's constant $k_{a}$ values 0.4 and the surface friction coefficient is $\mathrm{K}=k_{a}{ }^{2} /\left(\ln H / z_{o}\right)^{2}$. $z_{o}$ is the terrain roughness parameter, taken as 0.00001 .

\begin{tabular}{|c|c|c|c|c|c|c|c|}
\hline & \multicolumn{2}{|c|}{\begin{tabular}{|l|} 
Sea state 2 \\
\end{tabular}} & \multicolumn{2}{|c|}{\begin{tabular}{|l|} 
Sea state 3 \\
\end{tabular}} & \multicolumn{2}{|c|}{ Sea state 4} & \\
\hline & Cond. 1 & Cond. 2 & Cond. 1 & Cond. 2 & Cond. 1 & Cond. 2 & \\
\hline Vwind & 1 & 2 & & 15 & 1 & 9 & knots \\
\hline$T$ & 2.355 & 2.211 & 2.36 & 2.21 & 2.355 & 2.211 & $\mathrm{~m}$ \\
\hline$A_{L}$ & 323.22 & 330.26 & 323.22 & 330.26 & 323.22 & 330.26 & $\mathrm{~m}^{2}$ \\
\hline$L_{O A}$ & 49.24 & 49.24 & 49.24 & 49.24 & 49.24 & 49.24 & $\mathrm{~m}$ \\
\hline$H_{C}$ & 4.00 & 4.10 & 4.00 & 4.10 & 4.00 & 4.10 & $\mathrm{~m}$ \\
\hline$H_{L}$ & 6.56 & 6.71 & 6.56 & 6.71 & 6.56 & 6.71 & $\mathrm{~m}$ \\
\hline$q_{S}$ & 22.72 & 22.72 & 22.72 & 22.72 & 22.72 & 22.72 & $\mathrm{~N} / \mathrm{m}^{2}$ \\
\hline$q_{M}$ & 18.11 & 18.18 & 28.18 & 28.28 & 45.41 & 45.56 & $\mathrm{~N} / \mathrm{m}^{2}$ \\
\hline$q_{H L}$ & 21.35 & 21.42 & 33.22 & 35.35 & 53.53 & 53.70 & $\mathrm{~N} / \mathrm{m}^{2}$ \\
\hline$q_{T}$ & 18.89 & 18.95 & 29.39 & 53.07 & 47.35 & 47.51 & $\mathrm{~N} / \mathrm{m}^{2}$ \\
\hline$q_{A}$ & 41.60 & 41.66 & 52.10 & 53.07 & 70.06 & 70.22 & $\mathrm{~N} / \mathrm{m}^{2}$ \\
\hline$M_{\text {wind }} / C_{H}(\phi)$ & 9.01 & 9.42 & 11.28 & 11.80 & 15.17 & 15.87 & $\mathrm{t} \mathrm{m}$ \\
\hline
\end{tabular}

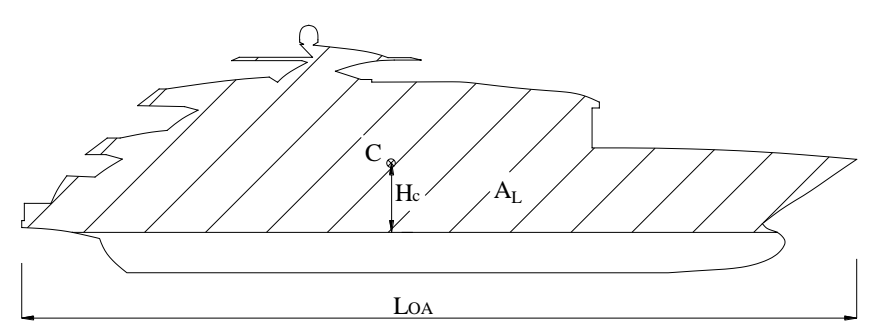

Fig. 11.- Definition of parameters for wind moment estimation

In Table III, results of the implementation of the described procedure is shown: (17) in (15), (16) in (14), $q_{S}$ and (14) in (13), and, finally evaluating expression (11).

TABLE III

ESTIMATION OF WIND MOMENT

\section{G. Results of simulations:}

With the above values, simulations are developed applying the Runge-Kutta $4^{\text {th }}$ order algorithm with fixed time interval [16] to equation (2). The ship is assumed to travel at 12 knots as receives irregular waves at sea states 2, 3 and 4., from the beam. Time increment is 0.0075 seconds, and the simulations are developed during 1200 seconds; this small increment is selected to describe adequately the control function and facilitate the numerical integration for the convolution. To determine the influence of each damping device, the procedure is run with the original hull (No BK No Foil), then with bilge 
keels (BK No Foil), with foils only (Foil), and, finally with bilge keels and foils (BK Foil) together. In Figs. 12 and 13 short records of roll angle in degrees from the simulations are presented. The effect of the wind is shown, with the roll oscillations around a small angle of heel.

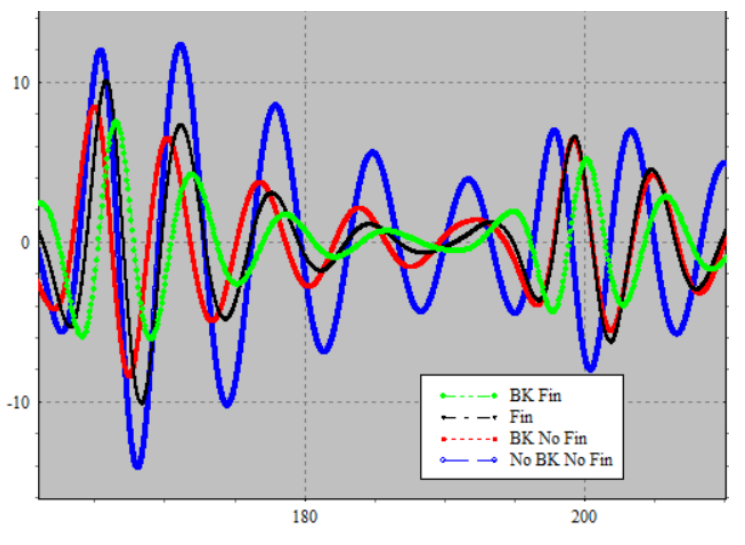

time, sec

Fig. 12.- Angle of heel in degrees as a function of time, condition 1, SS3

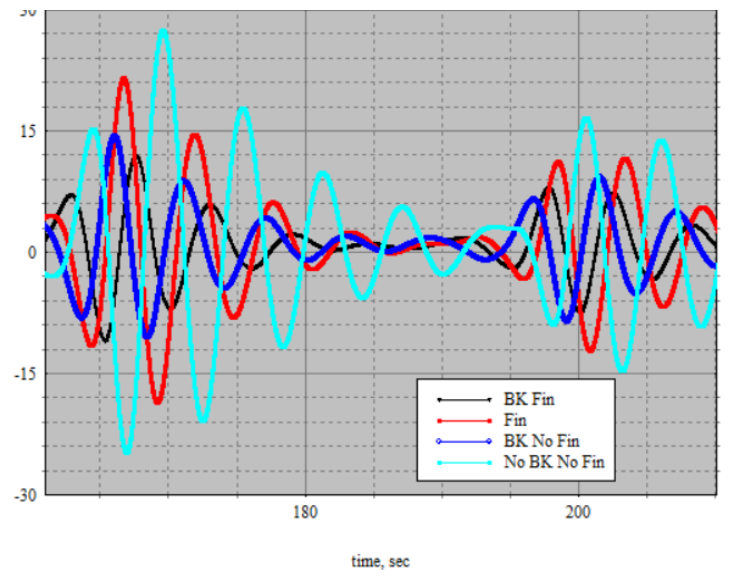

Fig. 13.- Angle of heel in degrees as a function of time, condition 2, SS3

In Fig. 14 variation of fin angle is plotted for both ship loading conditions. Values in condition 2 are higher than those in the first since in that situation roll angles tend to be higher, and the system responds by producing more counter-moment. The maximum foil angle is about $30^{\circ}$.

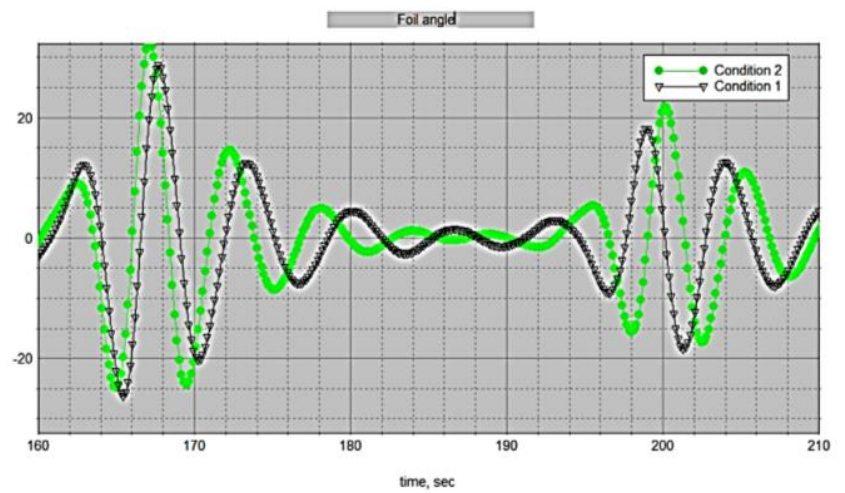

Fig. 14.- Foil angle in time
To check the correct operation of the foil control system, moments from waves and foils for both load cases are shown in Fig. 15. Action from foils (green) tends to have different sign than that from the waves (light blue), that is, they try to oppose them, but its values are smaller.
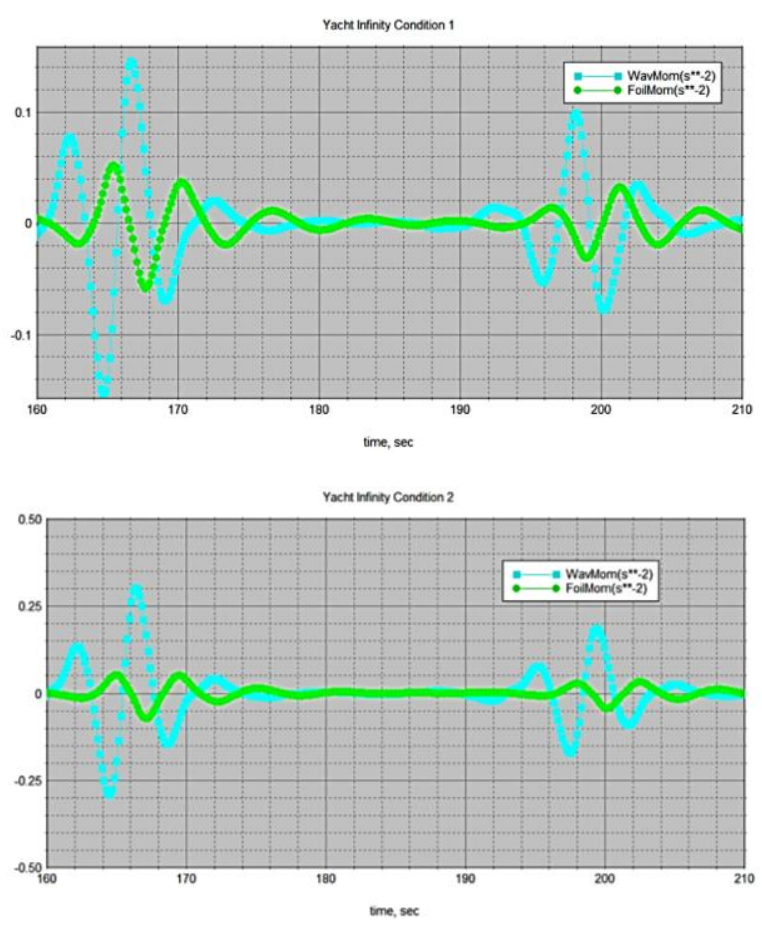

Fig. 15.- Wave and foil moments in time

With the results from simulations, the spectral density of the various response functions is calculated using Fourier transform, see Figs. 16 and 17 for SS3. From those curves, the mean square, $R M S^{2}$ which corresponds to the area under the curve is calculated. In all of these figures, natural frequencies are marked as vertical dashed lines. In Table IV, $R M S$ values of roll angle, roll velocity, roll acceleration, and, specific wave moment excitation is compared in the four configurations. Also in Fig. 18, variations of roll acceleration $R M S$ values are presented, as function of significative wave height.

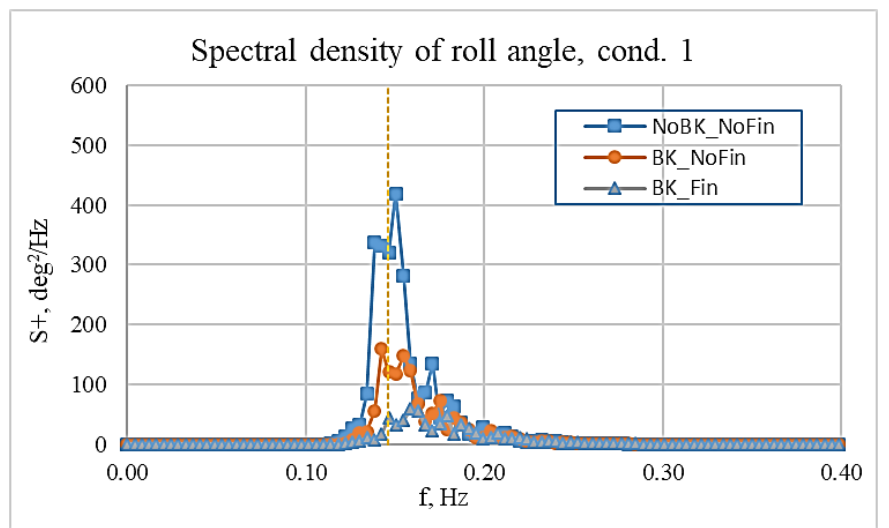




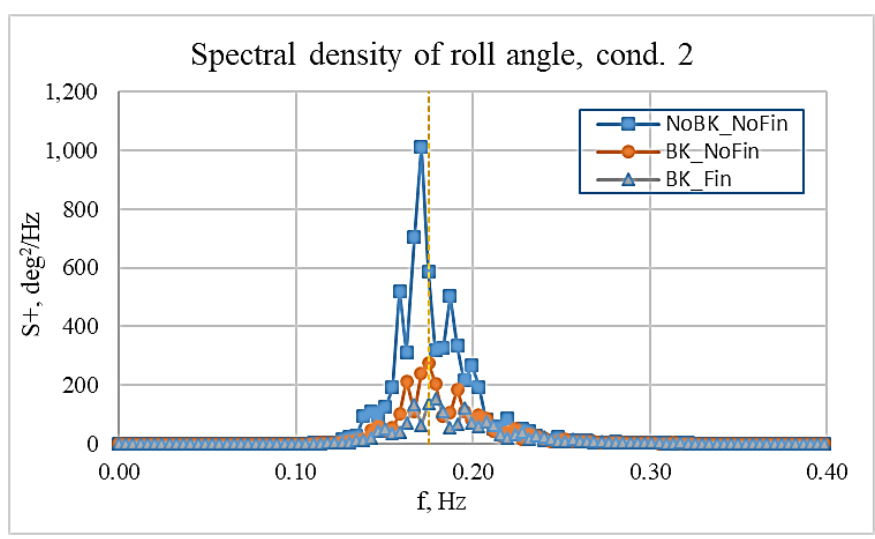

Fig. 16.- Spectral density of roll angle
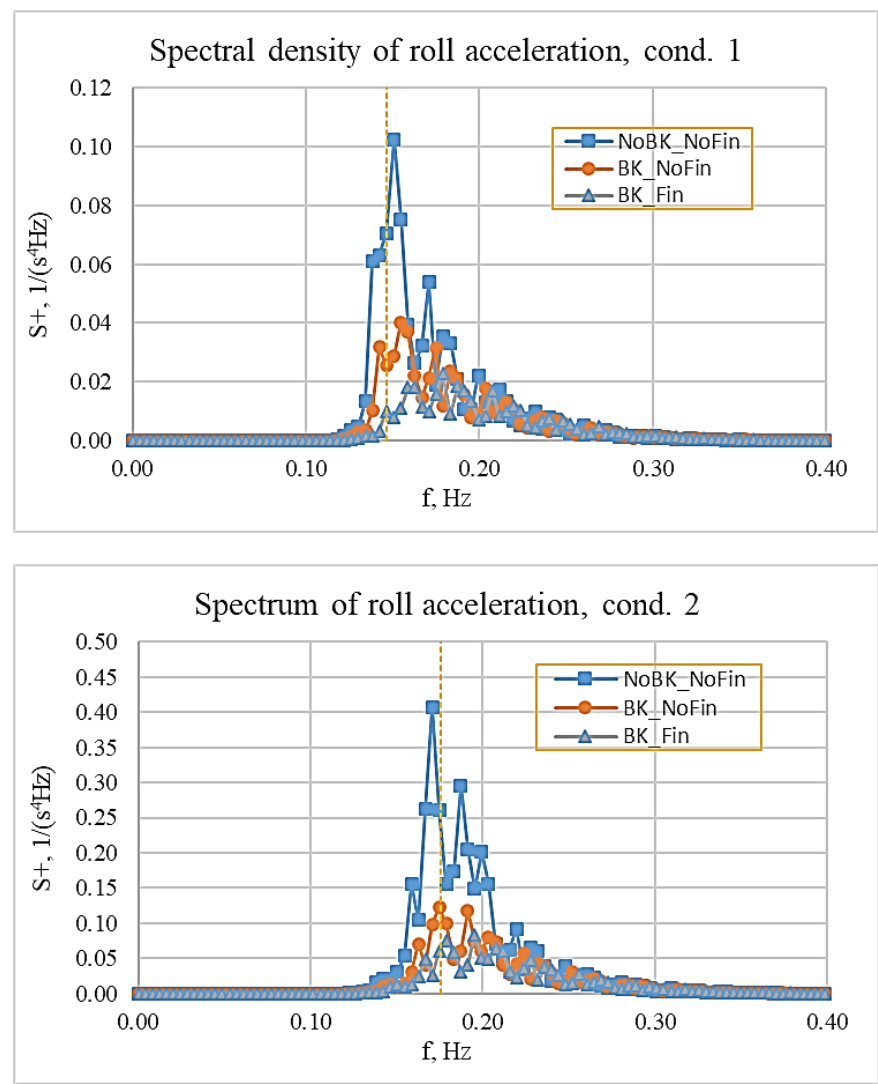

Fig. 17.- Spectral density of roll acceleration

TABLE IV

RMS VALUES OF SHIP RESPONSE FOR DIFFERENT SEA STATES

\begin{tabular}{|c|c|c|c|c|c|c|c|c|}
\hline \multirow{2}{*}{\multicolumn{2}{|c|}{ Sea state 2}} & \multicolumn{2}{|c|}{ Roll angle } & \multicolumn{2}{|c|}{ Roll vel. } & \multicolumn{2}{|c|}{ Roll accel. } & \multirow{2}{*}{\begin{tabular}{|c|} 
Wave mom \\
$1 / \mathrm{s}^{2}$
\end{tabular}} \\
\hline & & $\operatorname{deg}$ & & $1 / \mathrm{s}$ & & $1 / \mathrm{s}^{2}$ & & \\
\hline & No BK No Fin & 0.85 & $1100 \%$ & 0.018 & $100 \%$ & 0.023 & $100 \%$ & 0.013 \\
\hline & BK No & 0.80 & & 17 & & 022 & & .013 \\
\hline & Fin & 0.75 & & 017 & & 0.023 & $99 \%$ & 0.013 \\
\hline & BK Fi & 0.71 & & .016 & $89^{\circ}$ & .022 & $94 \%$ & 0.013 \\
\hline \multirow{4}{*}{$\begin{array}{l}\text { Z̃ } \\
\tilde{z} \\
\tilde{z}\end{array}$} & No BK No Fin & 2.25 & & & 100 & 0.064 & $\%$ & .026 \\
\hline & \begin{tabular}{|l|} 
BK No Fin \\
\end{tabular} & 1.68 & & & & 0.052 & & .026 \\
\hline & \begin{tabular}{|l|} 
Fin \\
\end{tabular} & 1.78 & $79 \%$ & 0.041 & $83 \%$ & 0.056 & $88 \%$ & 0.026 \\
\hline & BK Fin & 1.44 & $64 \%$ & 0.034 & $69 \%$ & 0.047 & $75 \%$ & 0.026 \\
\hline
\end{tabular}

\begin{tabular}{|c|c|c|c|c|c|c|c|c|}
\hline \multirow{2}{*}{\multicolumn{2}{|c|}{ Sea state 3}} & \multicolumn{2}{|c|}{ Roll angle } & \multicolumn{2}{|c|}{ Roll vel. } & \multicolumn{2}{|c|}{ Roll accel. } & \multirow{2}{*}{$\begin{array}{c}\text { Wave mom } \\
1 / \mathrm{s}^{2}\end{array}$} \\
\hline & & deg & & $1 / \mathrm{s}$ & & $1 / \mathrm{s}^{2}$ & & \\
\hline \multirow{4}{*}{ త్ } & No BK No Fin & 3.30 & $100 \%$ & 0.057 & $100 \%$ & 0.059 & $100 \%$ & 0.021 \\
\hline & BK No Fin & 2.27 & $69 \%$ & 0.041 & $72 \%$ & 0.045 & $77 \%$ & 0.021 \\
\hline & Fin & 1.88 & $57 \%$ & 0.036 & $64 \%$ & 0.042 & $72 \%$ & 0.021 \\
\hline & BK Fin & 1.59 & $48 \%$ & 0.031 & $55 \%$ & 0.037 & $63 \%$ & 0.021 \\
\hline \multirow{4}{*}{$\begin{array}{l}\text { N } \\
\text { है }\end{array}$} & No BK No Fin & 5.15 & $100 \%$ & 0.101 & $100 \%$ & 0.119 & $100 \%$ & 0.041 \\
\hline & \begin{tabular}{|l} 
BK No Fin \\
\end{tabular} & 3.17 & $62 \%$ & 0.065 & $64 \%$ & 0.080 & $67 \%$ & 0.041 \\
\hline & \begin{tabular}{|l|} 
Fin \\
\end{tabular} & 3.58 & $70 \%$ & 0.074 & $73 \%$ & 0.093 & $78 \%$ & 0.041 \\
\hline & BK Fin & 2.60 & $51 \%$ & 0.055 & $54 \%$ & 0.070 & $59 \%$ & 0.041 \\
\hline \multirow{2}{*}{\multicolumn{2}{|c|}{ Sea state 4}} & \multicolumn{2}{|c|}{ Roll angle } & \multicolumn{2}{|c|}{ Roll vel. } & \multicolumn{2}{|c|}{ Roll accel. } & Wave mon \\
\hline & & deg & & $1 / \mathrm{s}$ & & $1 / \mathrm{s}^{2}$ & & $1 / \mathrm{s}^{2}$ \\
\hline \multirow{4}{*}{$\overrightarrow{\overline{0}}$} & No BK No Fin & 6.92 & $100 \%$ & 0.110 & $100 \%$ & 0.103 & $100 \%$ & 0.031 \\
\hline & BK No Fin & 3.94 & $57 \%$ & 0.065 & $60 \%$ & 0.065 & $63 \%$ & 0.031 \\
\hline & Fin & 4.00 & $58 \%$ & 0.068 & $62 \%$ & 0.070 & $68 \%$ & 0.031 \\
\hline & BK Fin & 2.62 & $38 \%$ & 0.046 & $42 \%$ & 0.049 & $48 \%$ & 0.031 \\
\hline \multirow{4}{*}{ 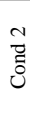 } & No BK No Fin & 8.23 & $100 \%$ & 0.146 & $100 \%$ & 0.157 & $100 \%$ & 0.057 \\
\hline & BK No Fin & 4.56 & $55 \%$ & 0.085 & $58 \%$ & 0.097 & $62 \%$ & 0.057 \\
\hline & Fin & 6.11 & $74 \%$ & 0.114 & $78 \%$ & 0.128 & $82 \%$ & 0.057 \\
\hline & BK Fin & 3.73 & $45 \%$ & 0.071 & $49 \%$ & 0.083 & $53 \%$ & 0.057 \\
\hline
\end{tabular}
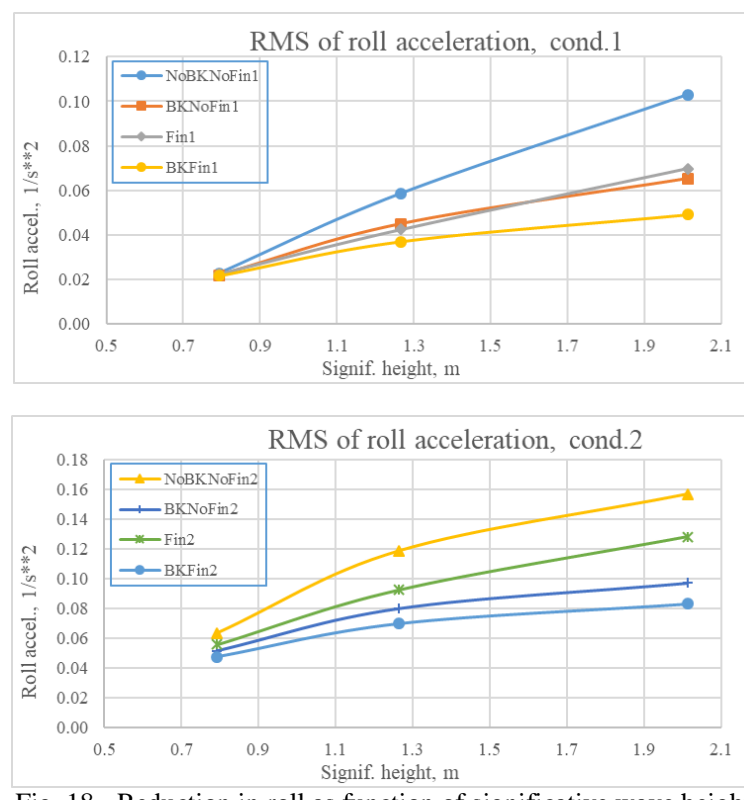

Fig. 18.- Reduction in roll as function of significative wave height

Comparing Figs. 12 and 13, the roll response is higher in load condition 2. This is the result of the excitability of the condition, see Fig. 4; notice that the modal frequency of the sea state 3 , is very close to the natural frequency in the second loading condition. In the first loading condition, there are two close peaks, one at the natural frequency and the other at the frequency of maximum spectral sea elevation.

In both time registers, Figs. 12 and 13, it is noticeable the reduction with each device. Results are summarized in Table IV and Fig. 18. Main point from these results is that the attenuation from each one of the devices does not add to the total. This is due to the nonlinear relationship between bilge keel damping and the response amplitude, and also because the active fins produce a moment which counteracts that from the waves. For load condition 1, even though the foil has a much smaller area, they produce as much reduction as the bilge keels.

Aspect ratio, $\tilde{A}=$ width/length, of bilge keels is an important parameter for its efficiency in reduction of roll 
oscillation, but it also means an increase in ship resistance. In Lloyd [4] comparison of two bilge keels, one with width, $w$ : $0.5 \mathrm{~m}$ and length, $l: 60 \mathrm{~m}$, and, a second with $w: 1.0 \times l: 30 \mathrm{~m}$ is presented, for a frigate traveling at 20 knots in a moderately severe seaway $\left(h_{1 / 3}=5.5 \mathrm{~m}\right)$; the one with $\tilde{A}$ of $1 / 30$ reported a higher reduction in roll, $69 \%$ vs $77 \%$, in the beam waves case. In the present analysis, bilge keels have an aspect ratio of $w: 0.67 \mathrm{~m} \mathrm{x} l: 12.41$, which is $1 / 18.5$, which is about half that in the larger ship. So the proportions employed for the bilge keels of smaller ships are quite different from those for larger ones.

\section{INSTALLATION OF DEVICES}

Hull structuration:

Based on the forces generated by the bilge keels, following the IACS recommendations, the hull shell in the bilge sector has been reinforced. The scantling of the fixed bilge keels uses the same thickness of the bilge shell and keeps the distance between frames. Bilge keels have been installed on a doubler plate on the hull, in order to reinforce the bottom shell in this area.

The location of the bilge keels have been selected with the following considerations:

- Install the bilge keels, on the same streamline of the active fins, Fig. 19.

- Locate the fixed fins in one-third of the floating length

- Leave enough space in the front and rear of the dynamic fin, to facilitate ship docking.

- The entrance and exit angle of the bilge keels should be 45 degrees.

- The bilge keels end must coincide with a transverse frame or a bulkhead.

To estimate the necessary structure to install the stabilizer fins, the followed procedure is:

- $\quad$ Estimate Lift and Drag forces for various ship speeds and different rotations of dynamic fins.

- Using the finite element method, internal forces and moments required to clamp the fin to the bottom structure have been estimated. The structural tie has been carried out radially, extending the fixation beams to the primary structural elements, Fig. 21. All weld seams are double continuous, following AWS recommendations.

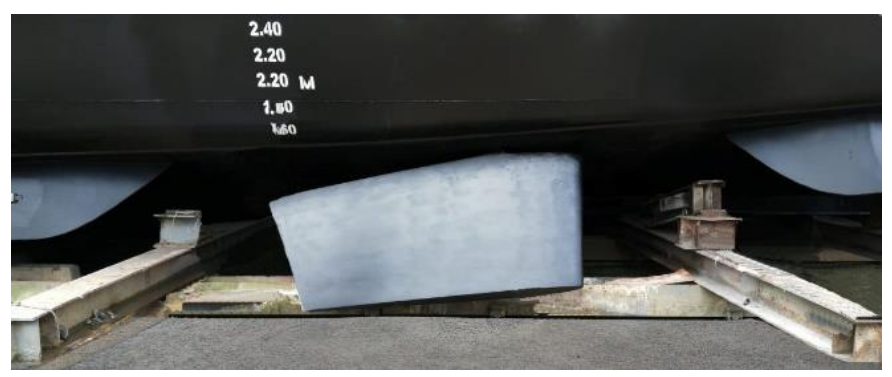

Fig. 19.- Installed fin with the ship in dry dock
According to the manufacturer's recommendations, it has been considered:

- The inclination of the dynamic fins must be between 25 and 35degrees, relative to the vertical line. In this particular case, 25degrees has been used, fig. 20.

- The longitudinal position of the fins should be in the central third of the flotation length.

- In the event that the bottom of the hull has a deadrise angle higher than 25degrees, install a leveling dome, softened at the ends to avoid excessive increase in drag.

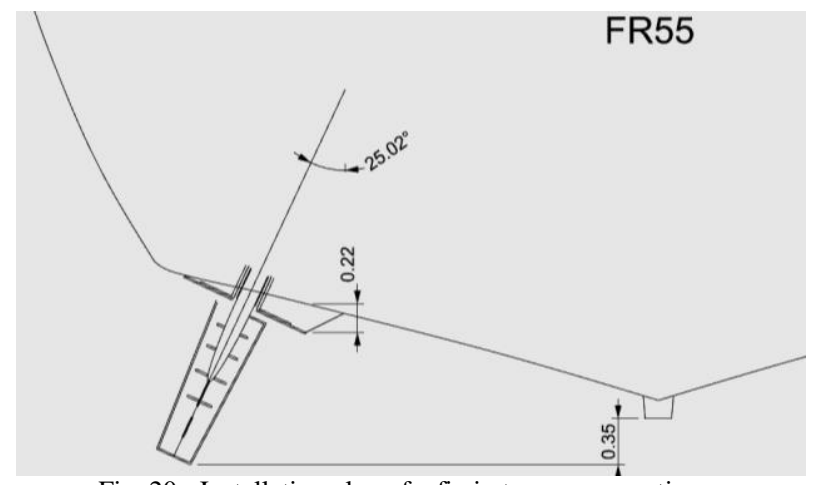

Fig. 20.- Installation plan of a fin in transverse section

- For the inside space around the dynamic fins, the distances necessary to install and operate the hydraulic units have been considered.

- The hydraulic circuit has been installed according to the manufacturer's recommendations. The complete circuit has been installed for a working pressure of 3000psi, pipe steel ASTM B53, seamless, Sch 80 and hydraulic hoses have been used. Before pressurizing the system, the inside of the circuit has been cleaned with pressurized air, to remove the waste, swarf, and then an internal nitrogen wash is applied.

- The hydraulic system consists of: a 30hp electric hydraulic pump, power unit, frequency variator, accumulator charged with oil at 600 psi, gyroscope, solenoid control valves, and control panel located on the bridge for automatic operation, Fig. 22.

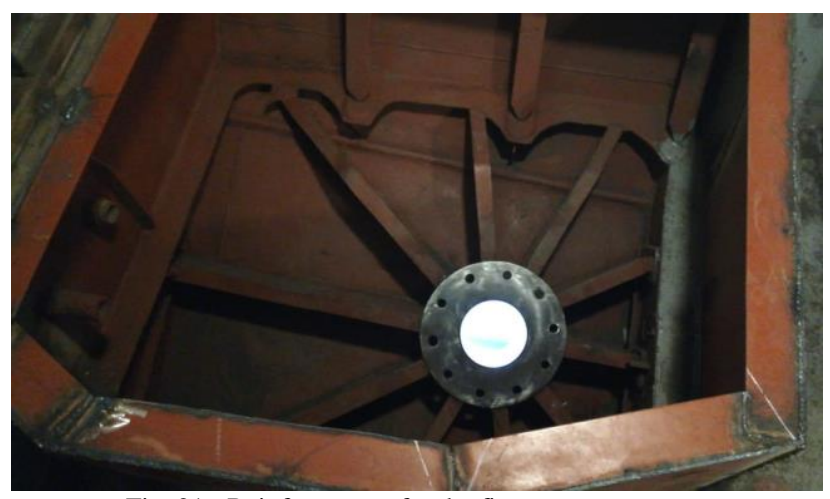

Fig. 21.- Reinforcement for the fin support 


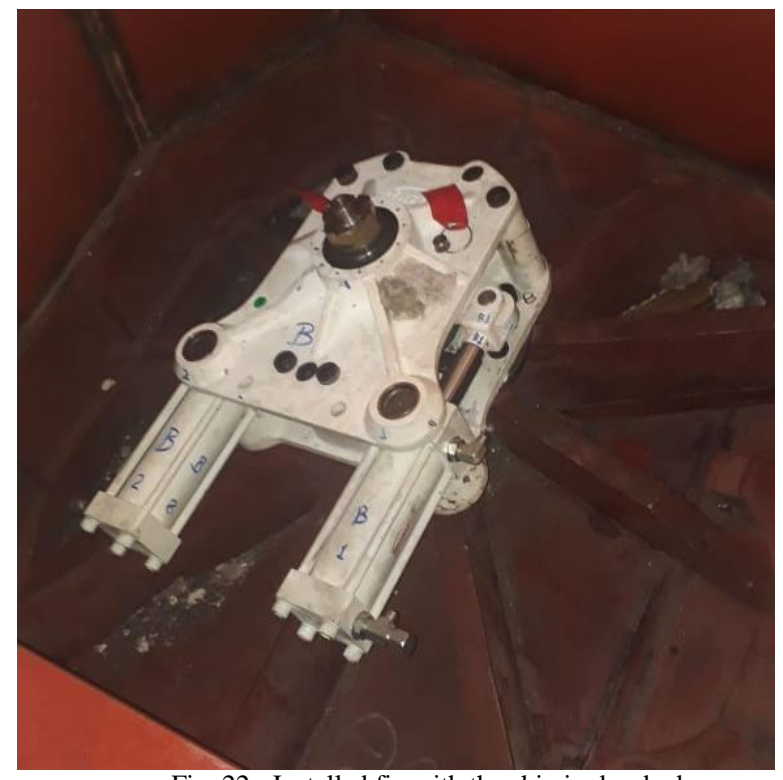

Fig. 22.- Installed fin with the ship in dry dock

\section{COST-BENEFIT ANALYSIS}

Due to the breadth of the yacht, there were strong rolling accelerations that produced discomfort to the passengers. For this reason, a preliminary study began to analyze which options were appropriate to mitigate these accelerations. Three options or their possible combinations have been considered:

\section{Bilge keels}

2. Fin stabilizer

3. Passive rolling tank

In each option, the percentage of roll damping that could be offered and what the benefit of the combination of each of these options would have been estimated. For the bilge keel option, it was estimated that between $15-20 \%$ in attenuation could be achieved for the rolling angle.

In the case of the stabilizer fins, it was estimated that with the size indicated above, it can be achieved approximately $50 \%$ roll attenuation. In the case of a passive rolling tank, it was expected to achieve an attenuation of approximately $35 \%$, however, the hull habitability arrangement should be modified excessively. For this reason, it was decided to use the combination of bilge keels with stabilizer fin, expecting to reach between [70 to $80 \%$ ] of roll attenuation, as demonstrated by the numerical simulations. Preliminary and comparative analysis of costs between the mentioned options for ship stabilization are shown is Table V.

The combination of options No. 1 and No. 2, was used to complete the construction and the installation work simultaneously. The installation time in dry-dock were approximately of 6 to 7 weeks without including the manufacturing and delivery time of the fin stabilizer.
TABLE V

COMPARISON OF COST AND TIME FOR EACH OPTION

\begin{tabular}{|c|c|c|}
\hline Devices & Cost & $\begin{array}{c}\text { Time } \\
\text { [weeks] }\end{array}$ \\
\hline \multicolumn{3}{|l|}{ 1. Bilge keels: } \\
\hline a. Construction / Installation & $\$ 40,000$ & \\
\hline \multicolumn{3}{|l|}{ b. Equipment ex-work } \\
\hline c. Modification of accommodations & $\$ 10,000$ & \\
\hline \multicolumn{3}{|l|}{ d. General expenses } \\
\hline e. Dry dock time & & 4 \\
\hline \multicolumn{3}{|l|}{ 2. $\quad$ Fin stabilizer: } \\
\hline a. Construction / Installation & $\$ 150,000$ & \\
\hline b. Equipment ex-work & $\$ 200,000$ & \\
\hline c. Modification of accommodations & & \\
\hline d. General expenses & $\$ 50,000$ & \\
\hline e. Dry dock time & & 6 to 7 \\
\hline \multicolumn{3}{|l|}{ 3. Passive Rolling tank: } \\
\hline a. $\quad$ Construction cost & $\$ 80,000$ & \\
\hline b. Equipment ex-work & & \\
\hline c. Modification of accomodations & $\$ 150,000$ & \\
\hline d. General expenses & & \\
\hline e. Dry dock time & & 10 to 12 \\
\hline
\end{tabular}

\section{CONCLUSIONS AND RECOMMENDATIONS}

Using the proposed numerical simulation it was possible to estimate the level of attenuation and establish the effectiveness of the bilge keels and dynamic active fins. This allowed a comparison of their effect on the dynamic response of a 49-m length overall monohull type ship, sailing at constant velocity with beam irregular waves. In the present case, in ship load condition 1 active foils with an smaller area produce as much attenuation in roll angle and acceleration as the bilge keels. In the other load condition, bilge keels show a better performance. The designer engineer must be aware that both effects are not going to add up algebraically; its effects should be considered simultaneously due to the nonlinearity of the problem and to the different form of action.

Both devices analysed in this work may be damaged by the blocks when the ship goes to drydock for maintenance. So it is necessary to carefully define docking plan to avoid accidents. The retractability of the active fins may offer some advantage.

Cost for the bilge keels and the roll stabilization system for this 49-m long ship, are compared in the last part of this analysis. Bilge keels are cheaper to install and do not need power for its operation, but once installed they increase ship resistance. Since for smaller ships, it seems necessary to apply higher aspect ratios for these appendages, it is recommended to evaluate this increase in resistance. 


\section{ACKNOWLEDGMENT}

Our thanks to the Wesmar staff, manufacturer of the dynamic fins, for the assistance during the installation stage.

\section{BIBLIOGRAPHY}

[1] R. Bhattacharyya, Dynamics of Marine Vehicles, John Wiley and Sons, 1978.

[2] T. Pérez, Ship Motion Control - Course Keeping and Roll Stabilisation Using Rudder and Fins, Springer, 2005.

[3] D. Watson, Practical Ship Design, Vol. I, Elsevier Science Ltd.. Vol I, 2002.

[4] A. Lloyd, Seakeeping - Ship behavior in rough weather, A R J M Lloyd, 1998.

[5] Smith, T., and Thomas, W., "A survey of ship motion reduction devices," David Taylor Research Center DTRC/S HD- 1338-01, Bethesda, 1990.

[6] Kim, J.-H. and Kim, Y., "Study on Heel Stabilization for Cruise Ship By using Active Fin and Anti-Rolling Tank," in International Research Exchange Meeting of Ship and Ocean Engineering, Osaka, 2012.

[7] Tecnavin, "Technical report for the installation of active foil system," Guayaquil, 2018.

[8] Belenky, V.L. and Sevastianov, N.B., Stability and Safety of Ships - Risk of Capsizing, SNAME, 2007.

[9] A. Raff, "Program SCORES - Ship Structural Response in Waves. SSC-230," Ship Structure Committee, 1972.

[10] F. Tasai, "Hydrodynamic Force and Moment Produced by Swaying and Rolling Oscillation of Cylinders on the Free Surface," Reports of Research Institute for Applied Mechanics, Kyushu University, 1961.

[11] E. Lewandowski, The Dynamics of Marine Craft, Singapore: World Scientific Pub Co, 2003.

[12] Y. Himeno, "Ship roll damping: state of the art," Dep. of Naval Architecture and Marine Engineering, U. of Michigan, rep.232, Ann Arbor, 1981.

[13] Lewis, E.V., ed., Principles of Naval Architecture, vol. III, SNAME, 1988.

[14] Fujiwara, T, and Ueno, M., "Cruising Performance of a Large Passenger Ship in Heavy Sea," in Proceedings of the Sixteenth International Offshore and Polar Engineering Conference, 2006.

[15] Det Norske Veritas, "Environmental Conditions and Environmental Loads. Recommended Practice DNVGLRP-C205," DNVGL, Oslo, 2019.

[16] W. Press, Numerical Recipes in Fortran 90, Cambridge University Press, 2014.
ANNEX

In the following drawing, it is shown the general structures used to clamp the fins support, following the manufacturer's recommendations.

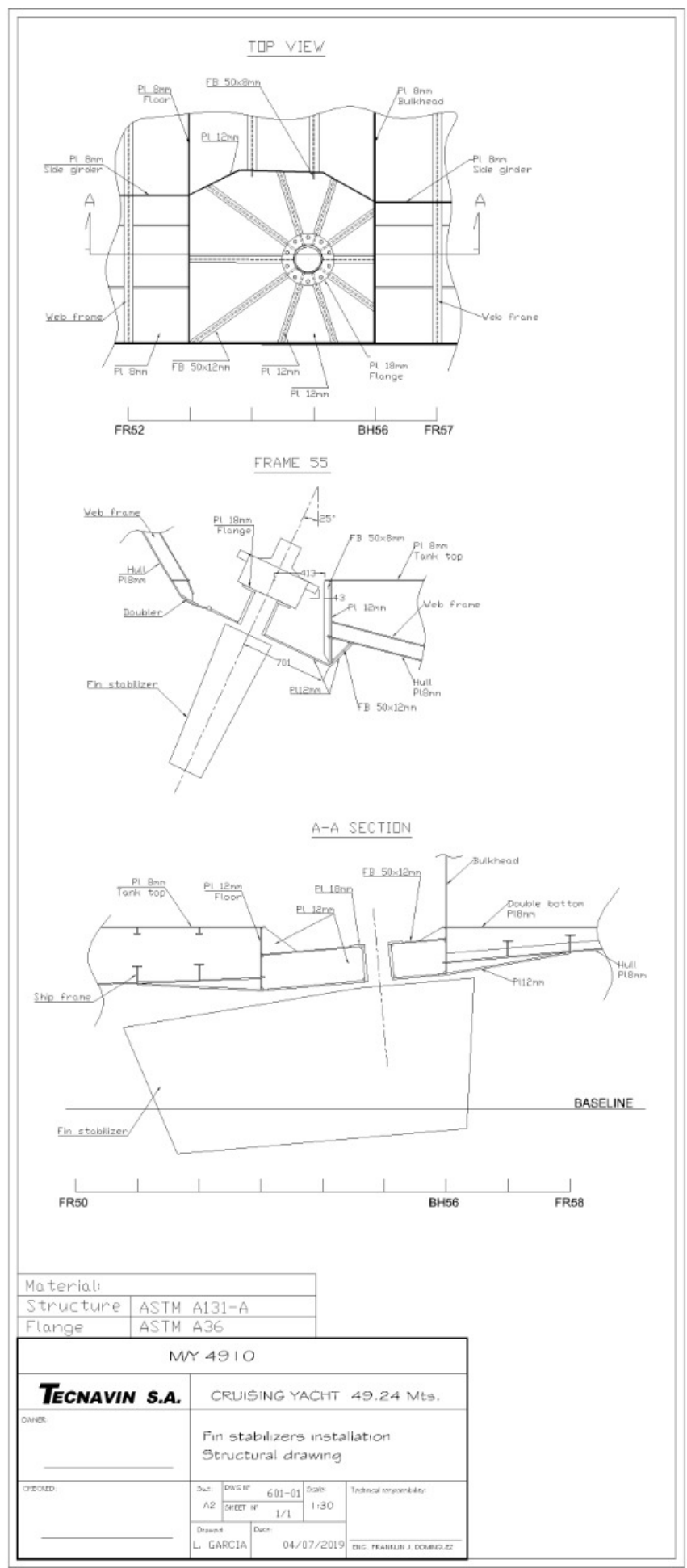

